\title{
Influence of Solar Radiation and Wet Processing on the Final Quality of Arabica Coffee
}

\author{
Lucas Louzada Pereira (D, ${ }^{1}$ Rogério Carvalho Guarçoni, ${ }^{2}$ \\ Wilton Soares Cardoso $\left(\mathbb{D},{ }^{3}\right.$ Renato Côrrea Taques, ${ }^{2}$ Taís Rizzo Moreira $\left(\mathbb{D},{ }^{4}\right.$ \\ Samuel Ferreira da Silva, ${ }^{4}$ and Carla Schwengber ten Caten ${ }^{1}$
${ }^{1}$ Federal University of Rio Grande do Sul, Av. Osvaldo Aranha, $n$ 99/5 Andar, Bom Fim, 90035-190 Porto Alegre, RS, Brazil
${ }^{2}$ Capixaba Institute for Technical Assistance, Research and Rural Extension/Department of Statistics, Rua Afonso Sarlo, 160 Bento Ferreira, 29052-010 Vitória, ES, Brazil
${ }^{3}$ Federal Institute of Espírito Santo/Food Science and Technology Program, Rua Elizabeth Minete Perim, S/N. Bairro São Rafael. 29375-000 Venda Nova do Imigrante, ES, Brazil
${ }^{4}$ Federal University of Espírito Santo/Center of Agricultural Sciences and Engineers, Av. Gov. Lindemberg, 316 Centro, 29550-000 Jerônimo Monteiro, ES, Brazil \\ Correspondence should be addressed to Lucas Louzada Pereira; lucaslozada@hotmail.com
}

Received 17 September 2017; Revised 5 December 2017; Accepted 10 January 2018; Published 11 February 2018

Academic Editor: Silvia C. C. Botelho

Copyright ( 2018 Lucas Louzada Pereira et al. This is an open access article distributed under the Creative Commons Attribution License, which permits unrestricted use, distribution, and reproduction in any medium, provided the original work is properly cited.

The coffee growing in the state of Espírito Santo has some peculiarities that differ from the other regions producing Arabica coffee in Brazil because it has a diversity of edaphoclimatic conditions that influence the final quality of the bean. This study aimed to demonstrate and quantify the effect of solar radiation and of different forms of wet process on the final quality of Arabica coffee in crops located in the altitude range of 950 meters, in order to understand what would be the best wet processing methods for the coffee cultivated to the East (sun-grown) and coffee cultivated to the South-Southeast (shade-grown). The results indicate that shading has a significant effect on the final quality of the Arabica coffee, as well as the type of wet process used to process the beans after harvest. Therefore, there is a need to study in depth the factors related to the processing, edaphoclimatic, and relief conditions inherent to mountain coffee cultivation.

\section{Introduction}

Arabica coffee in Brazil is usually produced in full sun and in areas that vary from 600 to 1400 meters of altitude, thus creating strata and different sensory perceptions associated with the flavors that each coffee can have due to edaphoclimatic and relief conditions and the amount of solar radiation that it receives.

According to Bosselmann et al. [1] there is a great controversy about the production of shaded and sun-grown coffee. On the other hand, for Somporn et al. [2], little has been discussed about the effect of shading on the final quality of the Arabica coffee. For Pinto Neto et al. [3], the observation of climate change on the planet causes new techniques to be developed, aiming at better adaptation of the crop to the new global climate scenario. Although shading and altitude are empirically known to have beneficial effects on coffee quality, only a few scientific studies have documented these effects [4]. Nevertheless, these kinds of studies need to consider the level of solar radiation as well as the average temperature.

It is known that, normally, coffee of colder regions receives higher grades than samples from warmer regions, regarding taste, aroma, sweetness, and body [5]. This factor is associated with the fact that high temperatures prevent the translocation of chemical compounds to fruits $[1,6,7]$.

Another line of research has argued that in addition to the factors mentioned above, it is necessary to study the effects of fermentation in postharvest processing. The works of Silva et 
al. [8], Silva et al. [9], and Pereira et al. [10] have discussed the significant effect of yeasts during the fermentation process, and those of Ribeiro et al. [11], Evangelista et al. [12], Masoud and Jespersen [13], and finally De Bruyn et al. [14] discussed the effect of bacteria. These microorganisms were detected in wet fermentation processes of the Arabica coffee, generating significant impacts on coffee quality. Gonzalez-Rios et al. [15] found that the removal of mucilage through degradation in water provided coffees with more fruity, floral, and caramel attributes and characteristics, while the removal of mucilage provided drier, more neutral beverages.

Thus, testing wet processing methods with induced fermentation, associated with the solar radiation index that the crop receives, constitutes an innovative action. Therefore, the hypothesis of this study is as follows: can the incidence of solar radiation, associated with different forms of wet processing with starter cultures, affect the quality of the coffee?

This study had the objective of evaluating the effect of solar radiation, associated with four different forms of wet processing in the sensory quality of Arabic coffee.

\section{Materials and Methods}

The experiments were conducted on a property located at 950 meters of altitude, as observed in Figure 1, using the variety Catuaí red 44. Table 1 indicates the geographic coordinates, the average duration of annual radiation, the average daily solar radiation for the year, and total solar radiation per year.

The climate of the region of Experiment 1 is characterized as hot and humid, with annual rainfall of 1200 to $1300 \mathrm{~mm}$ and average annual temperature of $19^{\circ} \mathrm{C}$. The climate of the region of Experiment 2 is also characterized as hot and humid, with an annual rainfall of 1200 to $1300 \mathrm{~mm}$, and average annual temperature of the $19^{\circ} \mathrm{C}$.

The soil samples from both experiments which were taken from the depth of $0-20 \mathrm{~cm}$ before the implantation of the experiment were analyzed.

The experiments and the management of the fertilization were carried out according to the results of the soil analysis, according to the Liming and Fertilization Manual for the State of Espírito Santo-5th approximation [16]. Fertilization was carried out in three parts from October to March. The soil correction of both experiments was carried out according to the Liming and Fertilization Manual for the State of Espírito Santo-5th approximation [16] according to the results of soil analysis.

Liming was performed in June for both experiments since the base saturation for the coffee crop should be $V=60 \%$ [16]. The phytosanitary control was conducted in October in a preventive way as typical in the region.

For the experimental control of the experiments it was observed that both are located at 950-meter altitude; the soil type of the two experimental areas is dystrophic Red-Dark Podzolic; the soil fertility conditions were corrected through fertilization and liming according to Prezotti et al. [16] in the two experiments; the climatic variations (temperature and rainfall) are similar in both areas, since they are close.
The fresh water used in the processing of the coffees in both experiments is in accordance with CONAMA $n^{\circ}$ $357 / 2005$ Resolution, which deals with the classification of water bodies [17].

Finally, both experiments were conducted in the same experimental design of randomized blocks, with the same number of replicates (05) and with the same treatments.

Experiment 02, East (sun-grown), received an average of 22.3 more minutes of solar radiation per day than the 01 , South-Southeast (shade-grown), representing 255.84 more $\mathrm{Wh} / \mathrm{m}^{2}$ per day, corresponding to $93.381,6 \mathrm{Wh} / \mathrm{m}^{2}$ more per year.

The South-Southeast and East experiments were conducted in a complete randomized block designed with five replicates and four treatments, one with starter culture for fermentation of Arabic coffee, Yeast Fermentation (Saccharomyces cerevisiae sp.), and the others with dry fermentation (Fully Washed) and with water (Washed) and pulped without fermentation (Semidry).

2.1. Raw Materials: Wet Processing. The raw materials used in the formulation of the must were coffee pulp, coffee husk, water, and yeast (Saccharomyces cerevisiae sp.).

Ten kilos of coffee were harvested per experimental plot in both experiments, presenting $85 \%$ of ripe fruits. After harvest, the fruits were processed according to the treatment.

2.2. Preparation of Musts. Of the four proposed treatments, one was prepared from the must, according to the process of patent BR1020160040531 (African drying beds), with yeast culture (Saccharomyces cerevisiae sp.) and coffee husk. The four treatments followed the following methods.

Treatment 01. It is dry fermentation must (Fully Washed, FW), $10 \mathrm{~kg}$ of peeled cherry coffee (pulp), and $5 \mathrm{~kg}$ of husk, without adding water to the process.

Treatment 02. It is fermentation must with water (Washed, W), $10 \mathrm{~kg}$ of peeled cherry coffee (pulp), $5 \mathrm{~kg}$ of husk, and 5 liters of water.

Treatment 03. It is fermentation must with yeast starter culture, Saccharomyces cerevisiae sp., (Yeast Fermentation, YF), $1 \%$ of the must (p/v), $10 \mathrm{~kg}$ of peeled cherry coffee (pulp), $5 \mathrm{~kg}$ of husk, 100 grams of yeast, and 5 liters of water.

Patent process (African drying beds) was deposited at the National Institute of Industrial Property.

Treatment 04. It is pulped coffee without mucilage withdrawal (Semidry, SD) and without any addition of microorganisms.

Musts 02 and 03 received water at $38^{\circ} \mathrm{C}$ and remained immersed in plastic fermentation tanks in the laboratory for 36 hours. The temperature of the fermentation room was stabilized at $21^{\circ} \mathrm{C}$.

Treatments 01,02 , and 03 remained in sealed tanks for 36 hours inside the fermentation room and, after this period, they were washed and taken to dry in African drying beds, such as in the farms. 

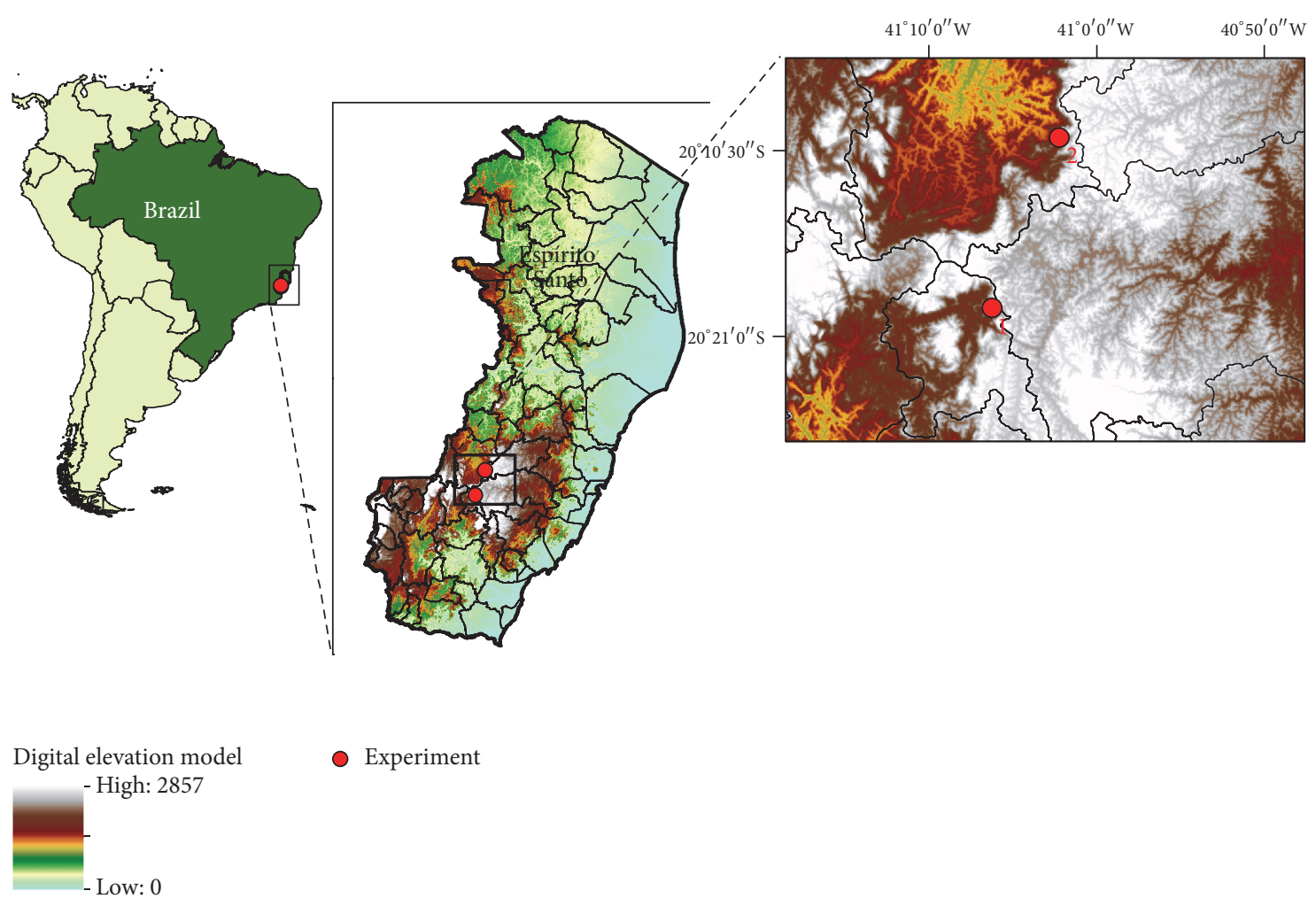

\begin{tabular}{cccc}
\hline Experiment & Annual rainfall $(\mathrm{mm})$ & Average annual temperature $\left({ }^{\circ} \mathrm{C}\right)$ & Soil types \\
\hline 1 & $1200-1300$ & 19 & Red-Dark Podzolic \\
2 & $1200-1300$ & 19 & Red-Dark Podzolic \\
\hline
\end{tabular}

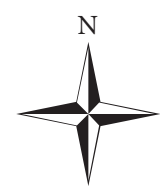

\begin{tabular}{|c|c|}
\hline \multicolumn{2}{|c|}{$(\mathrm{km})$} \\
\hline 50 & 100 \\
\hline
\end{tabular}

Geographic coordinates system

Datum: WGS 84

ZONA 24S

FIGURE 1: Location of the study area.

TABLE 1: Geographical coordinates and incidence of solar radiation for the two experiments.

\begin{tabular}{lccccc}
\hline Experiment & Latitude & Longitude & $\begin{array}{c}\text { Average annual radiation } \\
\text { duration (hours) }\end{array}$ & $\begin{array}{c}\text { Solar radiation, SR, daily } \\
\text { average for the year } \\
\left(\mathrm{Wh} / \mathrm{m}^{2}\right)\end{array}$ & $\begin{array}{c}\text { SR total year } \\
\left(\mathrm{WH} / \mathrm{m}^{2}\right)\end{array}$ \\
\hline 01 & -20.3263 & -41.1069 & 10.3673 & 4285.12 & 1564068.8 \\
02 & -20.1667 & -41.0375 & 10.7385 & 4540.96 & 1657450.4 \\
\hline
\end{tabular}

Source: [18]; Wh: Watt-hour.

Treatment 04 was pulped and taken to dry African drying beds. The process of fermentation occurred naturally, without any addition of microorganisms.

\subsection{Sensory Analyses. The sensory analyses were performed} by $06 \mathrm{Q}$-Graders, according to the method proposed by Pereira et al. [19]. The authors determined the number with simulation of the Bootstrap method.

The evaluations were carried out in the Laboratory of Research and Analysis in Coffee, LAPC, following the evidence protocol of the Specialty Coffee Association of America, SCAA. All tasters tested the 20 plots of each experiment. The SCAA protocol determines the overall quality of the coffee through an additive sum of 10 sensory parameters consisting of fragrance, flavor, aftertaste, acidity, body, uniformity, clean cup, sweetness, balance, and overall.

2.4. Statistical Analysis. A joint analysis of the experiments was performed. The results were compared with the Tukey test at $5 \%$ probability, followed by analysis of the main 
TABLE 2: Grades of the means of the sensory attributes for each treatment related to the crop located to the South-Southeast.

\begin{tabular}{|c|c|c|c|c|}
\hline Attributes & $\begin{array}{l}\text { Pulped without fermentation } \\
\text { (Semidry) }\end{array}$ & $\begin{array}{l}\text { Dry fermentation } \\
\text { (Fully Washed) }\end{array}$ & $\begin{array}{l}\text { Fermentation with } \\
\text { water (Washed) }\end{array}$ & Yeast Fermentation \\
\hline Fragrance & 7.94 & 7.99 & 8.29 & 8.01 \\
\hline Flavor & 7.72 & 7.80 & 7.99 & 7.80 \\
\hline Aftertaste & 7.62 & 7.56 & 7.78 & 7.66 \\
\hline Acidity & 7.81 & 7.80 & 7.98 & 7.72 \\
\hline Body & 7.62 & 7.61 & 7.80 & 7.65 \\
\hline Uniformity & 9.78 & 9.79 & 9.96 & 9.88 \\
\hline Clean cup & 9.85 & 9.86 & 9.92 & 9.93 \\
\hline Sweetness & 9.40 & 9.44 & 9.62 & 9.49 \\
\hline Balance & 7.58 & 7.58 & 7.74 & 7.63 \\
\hline Overall & 7.61 & 7.66 & 7.85 & 7.64 \\
\hline
\end{tabular}

TABLE 3: Grades of the means of the sensory attributes for each treatment related to the crop located to the East.

\begin{tabular}{lcccc}
\hline Attributes & $\begin{array}{c}\text { Peeled without } \\
\text { fermentation (Semidry) }\end{array}$ & $\begin{array}{c}\text { Dry process } \\
\text { (Fully Washed) }\end{array}$ & $\begin{array}{c}\text { Fermentation with } \\
\text { water (Washed) }\end{array}$ & $\begin{array}{c}\text { Fermentation with yeast } \\
\text { (Yeast Fermentation) }\end{array}$ \\
\hline Fragrance & 7.81 & 7.85 & 7.77 & 7.78 \\
Flavor & 7.61 & 7.66 & 7.65 & 7.63 \\
Aftertaste & 7.49 & 7.45 & 7.41 & 7.43 \\
Acidity & 7.64 & 7.77 & 7.65 & 7.55 \\
Body & 7.50 & 7.51 & 7.45 & 7.57 \\
Uniformity & 9.85 & 9.85 & 9.78 & 9.81 \\
Clean cup & 9.88 & 9.95 & 9.57 & 9.89 \\
Sweetness & 9.42 & 9.42 & 9.51 & 9.50 \\
Balance & 7.49 & 7.53 & 7.39 & 7.52 \\
Overall & 7.45 & 7.36 & 7.41 & 7.52 \\
\hline
\end{tabular}

components to group the treatments, using visual exams in graphical dispersions for the South-Southeast and East experiments, considering an accumulated variability above $70 \%$ adequate to perform the analysis. For statistical analysis, the SAEG software was used [11].

\section{Results and Discussion}

The results of the sensory analyses are presented in Tables 2 and 3, which show the mean values of the sensory attributes by treatment. All average results place the coffees in the range of specialty coffees by the SCAA protocol.

Table 4 presents the average results of the overall quality for the four treatments in the two environments, SouthSoutheast and East.

The results indicated that for the South-Southeast environment the fermentation must with water was superior in relation to pulped coffee without fermentation. However, it did not differ from the other treatments.

For the experiment located in the South-Southeast, the treatment with water presented higher overall quality than the experiment located in the East. In this way, the results corroborate the propositions of Joët et al. [4] and Muschler [20], indicating that the shading has exerted influence on coffee quality. It is known that usually the coffee in the colder and shaded region (higher altitude) receives higher grades regarding flavor, aroma, sweetness, and body than samples from warmer regions. For DaMatta [5], this factor is associated with the fact that the high temperatures prevent the translocation of chemical compounds to the fruits.

The results expressed in mean values for overall quality between the South-Southeast and East experiments were not statistically different from each other and did not confirm the same results found by Evangelista et al. [21] and Pereira et al. [22]. To these authors, the fermentation induced with yeast culture promoted quality gains to the observed coffees. This indicates that further studies are necessary to understand the modifications that may occur during the fermentation phase, providing greater clarification on the action of the microorganisms, as well as the competition between microorganisms that occurs during the fermentation phase with cultures starters.

It was verified in the experiment located to the East that the treatments did not differ among themselves at $5 \%$ of probability.

Table 5 shows the eigenvalues with simple and cumulative percentages of the total variance of the main components of the South-Southeast experiment. 
TABLE 4: Averages of the overall quality evaluated in four treatments and in two environments, Venda Nova do Imigrante, in 2015.

\begin{tabular}{|c|c|c|c|}
\hline \multirow{2}{*}{ Treatment } & \multicolumn{2}{|c|}{ Global quality } & \multirow{2}{*}{ Average } \\
\hline & South-Southeast & East & \\
\hline Dry fermentation (Fully Washed) & $83.06^{\mathrm{abA}}$ & $82.16^{\mathrm{aA}}$ & $82.61^{\mathrm{a}}$ \\
\hline Fermentation with water (Washed) & $84.86^{\mathrm{aA}}$ & $81.63^{\mathrm{aB}}$ & $83.25^{\mathrm{a}}$ \\
\hline Yeast Fermentation & $83.50^{\mathrm{abA}}$ & $82.24^{\mathrm{aA}}$ & $82.87^{\mathrm{a}}$ \\
\hline Pulped without fermentation (Semidry) & $82.63^{\mathrm{bA}}$ & $81.70^{\mathrm{aA}}$ & $82.17^{\mathrm{a}}$ \\
\hline Average & $83.51^{\mathrm{A}}$ & $81.93^{\mathrm{B}}$ & \\
\hline
\end{tabular}

Means followed by at least one same horizontal capital letter and at least one same lowercase vertical letter do not differ from one another by the Tukey test at $5 \%$ probability.

TABLE 5: Main components, their respective eigenvalues, and simple and accumulated percentages of the total variance of the South-Southeast experiment.

\begin{tabular}{lccc}
\hline Main component & Eigenvalues & Simple percentage & Accumulated percentage \\
\hline CP1 & 9.998819 & 99.98819 & 99.98819 \\
CP2 & 0.0008436559 & 0.00844 & 99.99662 \\
\hline
\end{tabular}

TABLE 6: Main components, their respective eigenvalues, and simple and accumulated percentages of the total variance of the East experiment.

\begin{tabular}{lccc}
\hline Main Component & Eigenvalues & Simple percentage & Accumulated percentage \\
\hline CP1 & 9.998897 & 99.98897 & 99.98897 \\
CP2 & 0.001005009 & 0.01005 & 99.99902 \\
\hline
\end{tabular}

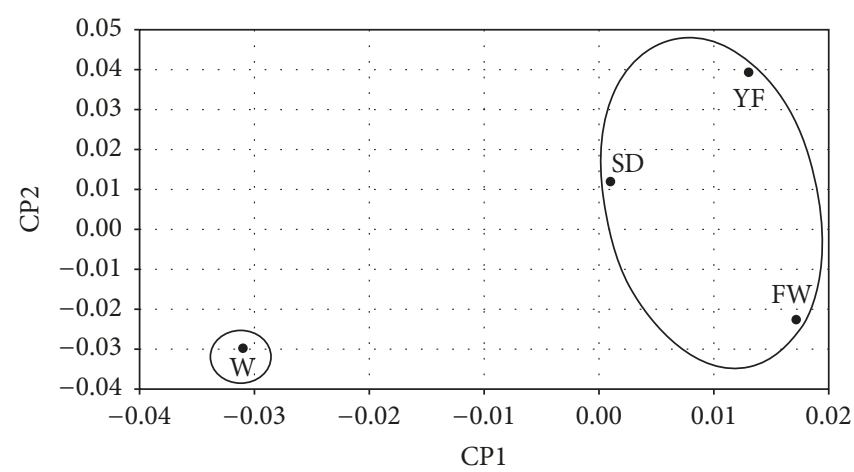

Figure 2: Diagram of dispersion in relation to the first two main components of the treatments: dry fermentation must-Fully Washed (FW), fermentation must with water-Washed (W), fermentation must with yeast-Yeast Fermentation (YF), and pulped without fermentation-Semidry (SD), from the South-Southeast (shade-grown) experiment.

Figure 2 presents the dispersion of the treatments of the South-Southeast experiment, based on the respective coordinates related to the first two main components, $\mathrm{CP} 1$ and CP2. The treatments were treatment with dry fermentation must (Fully Washed, FW), fermentation must with starters yeast cultures (Yeast Fermentation, YF), and pulped coffee without fermentation (Semidry, SD) form one group and the treatment fermentation with water (Washed, W) in another group. In addition, the two components absorbed $99.997 \%$ of the variation existing in the original features (Table 5).

The results expressed in Figure 2 indicate that for the condition of the experiment located in the South-Southeast, that is, shaded terrains, the fermentation with water, the method commonly adopted in Colombia, is grouped far from the other treatments.
Table 6 shows the eigenvalues and simple and accumulated percentages of the total variance of the East experiment.

Figure 3 shows the dispersion of the treatments of the East experiment based on the respective coordinates relative to the first two main components CP1 and CP2. The treatments with dry fermentation must (Fully Washed, FW), fermentation must with starters yeast cultures (Yeast Fermentation, YF), and pulped coffee without fermentation (Semidry, SD) form a group and the treatment fermentation with water (Washed, W) forms another group, and the two components absorbed 99.999\% of the variation existing in the original features (Table 6).

The analyzed data of the eastern crop show results similar to those of the experiment located in the South-Southeast, in relation to the main components. However, in the treatment 


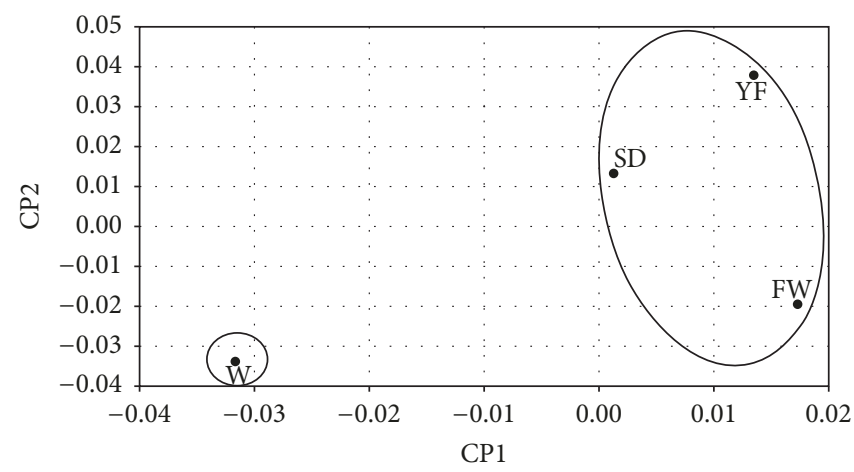

Figure 3: Diagram of dispersion in relation to the first two main components of the treatments: dry fermentation must-Fully Washed (FW), fermentation must with water-Washed (W), fermentation must with starters of yeast-Yeast Fermentation (YF), and pulped without fermentation-Semidry (SD), from the East experiment (sun-grown).

with water, the overall quality was higher for the SouthSoutheast environment when compared to the East, as shown in Table 4. This result can be explained by the action of the microorganisms to the detriment of the microbiota that is present in the two experiments. Evangelista et al. [21] have argued that the formation of the microbiota, the room temperature, and the $\mathrm{pH}$ of the must may undergo changes and modify the intensity and the way the microorganisms act during the fermentation process. The fruits of the coffee when being processed allow the emergence of a spontaneous or wild fermentation. The sugars and pectins present in the mucilage allow the growth of microorganisms, especially bacteria and yeasts.

Yet, the scientific literature contains virtually no studies on microbial interactions at a single cell level occurring on solid and liquid surfaces, involving fermentation microorganisms [23].

This fact may have influenced positively the fermentation with water for the experiment located in the South-Southeast and influenced it negatively in the experiment located in the East, confirming the need for greater monitoring during the fermentation stages of Arabica coffee [14].

Precisely because of the lack of clarification about the medium of fermentation within the coffee fruit, this hypothesis proposes a new perspective for science, the monitoring of the microbiota that is formed inside the coffee fruits and how it develops after harvesting under different fermentation conditions.

According to the perspective of Lee et al. [24], the effects of fermentation during the wet treatment on the aroma profile of coffee are not completely elucidated and are often neglected since the literature has argued that the main function of fermentation is the removal of the mucilage. For De Bruyn et al. [14], further studies should be undertaken to strengthen the understanding of the impact of the microbiota on coffee quality and provide robust data for the development of more controlled fermentation processes.

The coffee fermentation occurs to solubilize polysaccharides, which are present in the coffee pulp, after removal of the mucilage, facilitating the drying of the fruits. During the fermentation, microorganisms act in the degradation of the sugars present in the pulp, thereby creating metabolic routes and differentiated sensory patterns. For Velmourougane [25], it is important to study and understand the fermentation process to develop flavor and a high quality standard of coffee.

It is evident that fermentation is a complex process, involving several factors, with the action of different microorganisms that can act in the improvement, as in the loss, of quality. Consequently, it can contribute or not to the deterioration of the product's final taste, due to the kind of action they can take on processing. Hence the importance of knowing more about the action of the microbiota and about fermentation processes during the production of specialty coffees, in view of the opportunity to create more standardized processes that consider the described factors, aiming to promote quality improvements to the final product, as well as food safety to the consumer.

Developing and controlling processes in the production of specialty coffees have proved to be a complex task and often without a consensus on the best postharvest processing method, which may vary from region to region. Velmourougane [25] reinforces the need to study processing techniques, looking for ways to improve the final quality of Arabica coffee.

Results presented in Figure 4 corroborate with the data presented in Table 4, showing the values of the most significant sensory attributes for the fermentation with water treatment, in relation to the nonfermented (semidry), confirming the data of de Melo Pereira et al. [10] and Lee et al. [24].

Figure 5 shows the dispersion of the sensory attributes of the treatments related to the experiment in the East, corroborating with the results obtained in Table 4 for the overall quality of the Arabica coffee.

It is possible to understand that the washed fermentation can be an engine maker of new routes and nuances for the formation of the sensory features of the wet processed coffee, aiming at the potentialization and optimization of the quality curve of Arabica coffee.

On the difference between the fermentation methods, the results of Somporn et al. [2] indicated that shading exerts an influence on the formation of sugars, chlorogenic acids, and total phenolics. In addition to shading, DaMatta [5] 


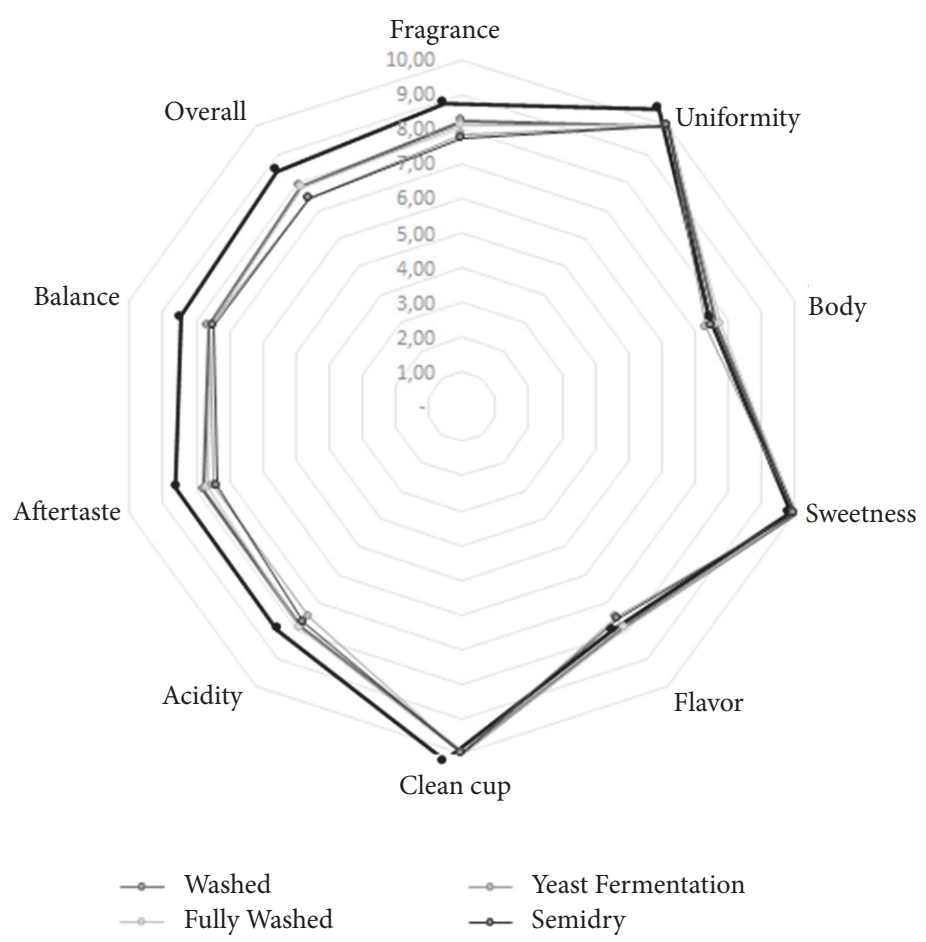

Figure 4: Average dispersion of attributes: fragrance, uniformity, clean cup, sweetness, flavor, acidity, body, aftertaste, balance, and overall, of the coffees located in the South-Southeast (shade-grown).

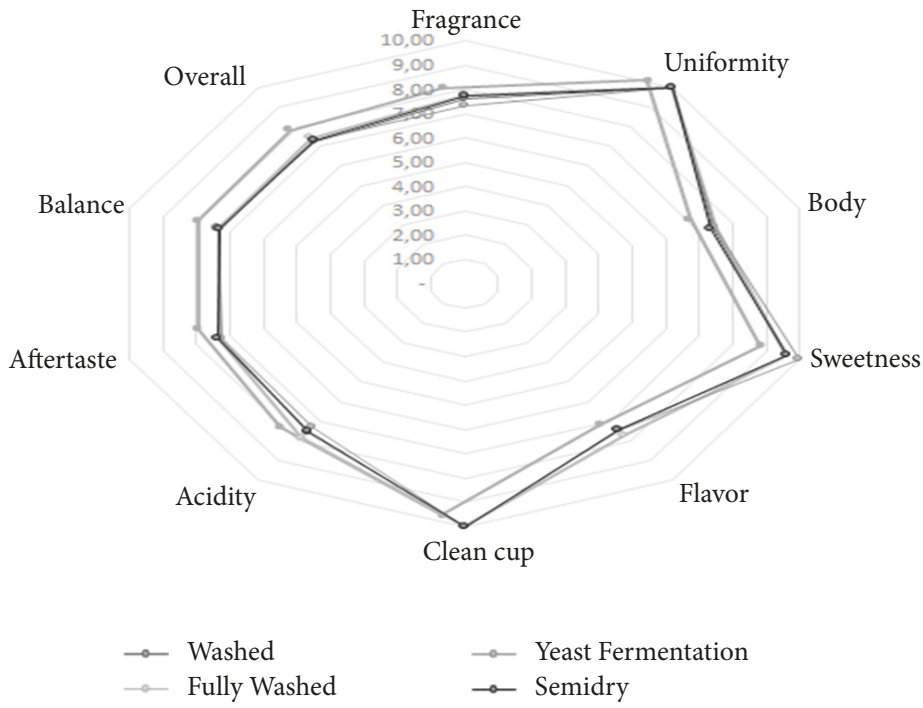

FIGURE 5: Average dispersion of the attributes: fragrance, uniformity, clean cup, sweetness, flavor, acidity, body, aftertaste, balance, and overall, of the coffees situated to the East (sun-grown).

argues that fruits that are formed under conditions of higher temperatures mature prematurely, preventing the complete translocation of compounds responsible for the typical aroma and flavor of the coffee.

Thus, the microbiota of the experiment located in the South-Southeast associated with the water-induced fermentation method contributed to the modification of the sensory characteristics, in relation to the experiment located in the East, area with higher solar incidence.

\section{Conclusion}

The overall quality of the coffees presented the most promising results for wet processing through water fermentation in 
relation to the nonfermentation method (Semidry) for the experiment located in the South-Southeast region.

The lower incidence of solar radiation in the crop had a significant effect on the overall quality of the Arabica coffee, associated with wet processing and water fermentation (Washed).

These results demonstrate and reinforce the condition of the environment; that is, the incidence of solar radiation can lead to changes in internal metabolites, creating a stress condition, and consequently different conditions for the development of microorganisms. However, this new hypothesis needs to be better clarified.

Variations with respect to the water fermentation method for the experiment located in the South-Southeast and East regions may be related to the action of the microorganisms present in the Arabica coffee and new research and studies are needed to deepen and to quantify the action of these microorganisms in loco.

\section{Conflicts of Interest}

The authors declare that there are no conflicts of interest regarding the publication of this paper.

\section{Acknowledgments}

The authors thank the Federal Institute of Espírito Santo for supporting this research and also for the translation and review of this article. They also thank National Council for Scientific and Technological Development (469058/20145), $\mathrm{CNPq}$, and Secretariat of Professional and Technological Education of the Ministry of Education (SETEC) for the availability of resources for research.

\section{References}

[1] A. S. Bosselmann, K. Dons, T. Oberthur, C. S. Olsen, A. Ræbild, and H. Usma, "The influence of shade trees on coffee quality in small holder coffee agroforestry systems in Southern Colombia," Agriculture, Ecosystems \& Environment, vol. 129, no. 1-3, pp. 253-260, 2009.

[2] C. Somporn, A. Kamtuo, P. Theerakulpisut, and S. Siriamornpun, "Effect of shading on yield, sugar content, phenolic acids and antioxidant property of coffee beans (Coffea Arabica L. cv. Catimor) harvested from north-eastern Thailand," Journal of the Science of Food and Agriculture, vol. 92, no. 9, pp. 1956-1963, 2012.

[3] J. N. Pinto Neto, M. I. N. Alvarenga, M. P. Correa, and C. C. Oliveira, "Efeito das variáveis ambientais na produção de café em um sistema agroflorestal," Coffee Science, vol. 9, no. 2, pp. 187-195, 2014.

[4] T. Joët, A. Laffargue, F. Descroix et al., "Influence of environmental factors, wet processing and their interactions on the biochemical composition of green Arabica coffee beans," Food Chemistry, vol. 118, no. 3, pp. 693-701, 2010.

[5] F. M. DaMatta, "Exploring drought tolerance in coffee: A physiological approach with some insights for plant breeding," Brazilian Journal of Plant Physiology, vol. 16, no. 1, pp. 1-6, 2004.

[6] B. Guyot, D. Gueule, J. C. Manez, J. J. Perriot, J. Giron, and L. Villain, "Influence de l'altitude et de l'ombrage sur la qualité des cafés Arabica," Juillet. Août, Plantations, Recherche, Développement, vol. 3, no. 4, pp. 272-283, 1996.

[7] B. Bertrand, P. Vaast, E. Alpizar, H. Etienne, F. Davrieux, and P. Charmetant, "Comparison of bean biochemical composition and beverage quality of Arabica hybrids involving SudaneseEthiopian origins with traditional varieties at various elevations in Central America," Tree Physiology, vol. 26, no. 9, pp. 12391248, 2006.

[8] C. F. Silva, L. R. Batista, L. M. Abreu, E. S. Dias, and R. F. Schwan, "Succession of bacterial and fungal communities during natural coffee (Coffea arabica) fermentation," Food Microbiology, vol. 25, no. 8, pp. 951-957, 2008.

[9] C. F. Silva, L. R. Batista, and R. F. Schwan, "Incidence and distribution of filamentous fungi during fermentation, drying and storage of coffee (Coffea arabica L.) beans," Brazilian Journal of Microbiology, vol. 39, no. 3, pp. 521-526, 2008.

[10] G. V. M. Pereira, V. T. Soccol, A. Pandey et al., "Isolation, selection and evaluation of yeasts for use in fermentation of coffee beans by the wet process," International Journal of Food Microbiology, vol. 188, pp. 60-66, 2014.

[11] B. B. Ribeiro, L. M. V. L. Mendonça, G. A. Assis, J. M. A. de Mendonça, M. R. Malta, and F. F. Montanari, "Evaluation of the chemical and sensory characteristics of Coffea canephora Pierre and Coffea Arabica L. blends," Coffee Science, vol. 9, no. 2, pp. 178-186, 2014.

[12] S. R. Evangelista, M. G. da Cruz Pedrozo Miguel, C. de Souza Cordeiro, C. F. Silva, A. C. Marques Pinheiro, and R. F. Schwan, "Inoculation of starter cultures in a semi-dry coffee (Coffea arabica) fermentation process," Food Microbiology, vol. 44, pp. 87-95, 2014.

[13] W. Masoud and L. Jespersen, "Pectin degrading enzymes in yeasts involved in fermentation of Coffea arabica in East Africa," International Journal of Food Microbiology, vol. 110, no. 3, pp. 291-296, 2006.

[14] F. De Bruyn, S. J. Zhang, V. Pothakos et al., "Exploring the impacts of postharvest processing on the microbiota and metabolite profiles during green coffee bean production," Applied and Environmental Microbiology, vol. 83, no. 1, Article ID e02398-16, 2017.

[15] O. Gonzalez-Rios, M. L. Suarez-Quiroz, R. Boulanger et al., "Impact of "ecological" post-harvest processing on coffee aroma: II. Roasted coffee," Journal of Food Composition and Analysis, vol. 20, no. 3-4, pp. 297-307, 2007.

[16] L. C. Prezotti, J. A. Gomes, G. G. Dadalto, and J. A. Oliveira, "Manual de recomendação de calagem e adubação para o Estado do Espírito Santo - 5a aproximação," Vitória: SEEEA/ INCAPER/CEDAGRO, article 305, 2007.

[17] CONAMA - CONSELHO NACIONAL DE MEIO AMBIENTE (Brasil), "Resolução n 357, de 17 de março de 2005," Diário Oficial da União, pp. 58-63, 2015.

[18] GEOBASES. Sistema Integrado de Bases Geoespaciais do Estado do Espírito Santo. 2016, http://www.geobases.es.gov.br/ portal/.

[19] L. L. Pereira, R. C. Guarçoni, I. C. Pulini et al., "Tamanho ótimo do número de provadores de café com uso do protocolo SCAA," Simposio Internacional De Ingeniería Industrial: Actualidad $Y$ Nuevas Tendencias, vol. 9, 2016.

[20] R. G. Muschler, "Shade improves coffee quality in a sub-optimal coffee-zone of Costa Rica," Agroforestry Systems, vol. 51, no. 2, pp. 131-139, 2001.

[21] S. R. Evangelista, C. F. Silva, M. G. P. D. C. Miguel et al., "Improvement of coffee beverage quality by using selected 
yeasts strains during the fermentation in dry process," Food Research International, vol. 61, pp. 183-195, 2014.

[22] G. V. M. Pereira, E. Neto, V. T. Soccol, A. B. P. Medeiros, A. L. Woiciechowski, and C. R. Soccol, "Conducting starter culturecontrolled fermentations of coffee beans during on-farm wet processing: Growth, metabolic analyses and sensorial effects," Food Research International, vol. 75, pp. 348-356, 2015.

[23] R. F. Schwan and G. H. Fleet, Cocoa and Coffee Fermentation, Taylor \& Francis Group, LLC. CRC Press, 2015.

[24] L. W. Lee, M. W. Cheong, P. Curran, B. Yu, and S. Q. Liu, "Coffee fermentation and flavor - An intricate and delicate relationship," Food Chemistry, vol. 185, pp. 182-191, 2015.

[25] K. Velmourougane, "Impact of natural fermentation on physicochemical, microbiological and cup quality characteristics of Arabica and Robusta coffee," Proceedings of the National Academy of Sciences India Section B - Biological Sciences, vol. 83, no. 2, pp. 233-239, 2013. 


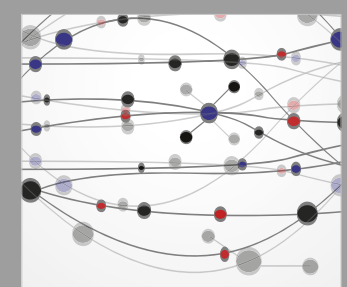

The Scientific World Journal
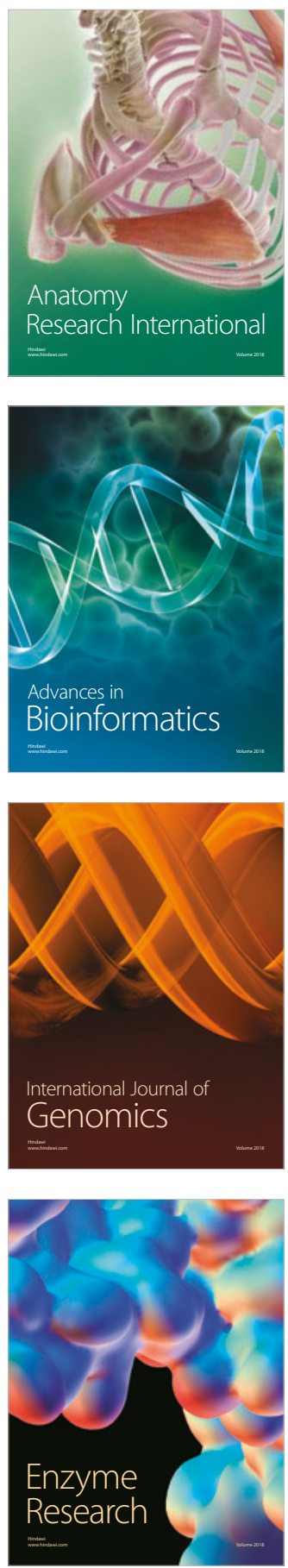
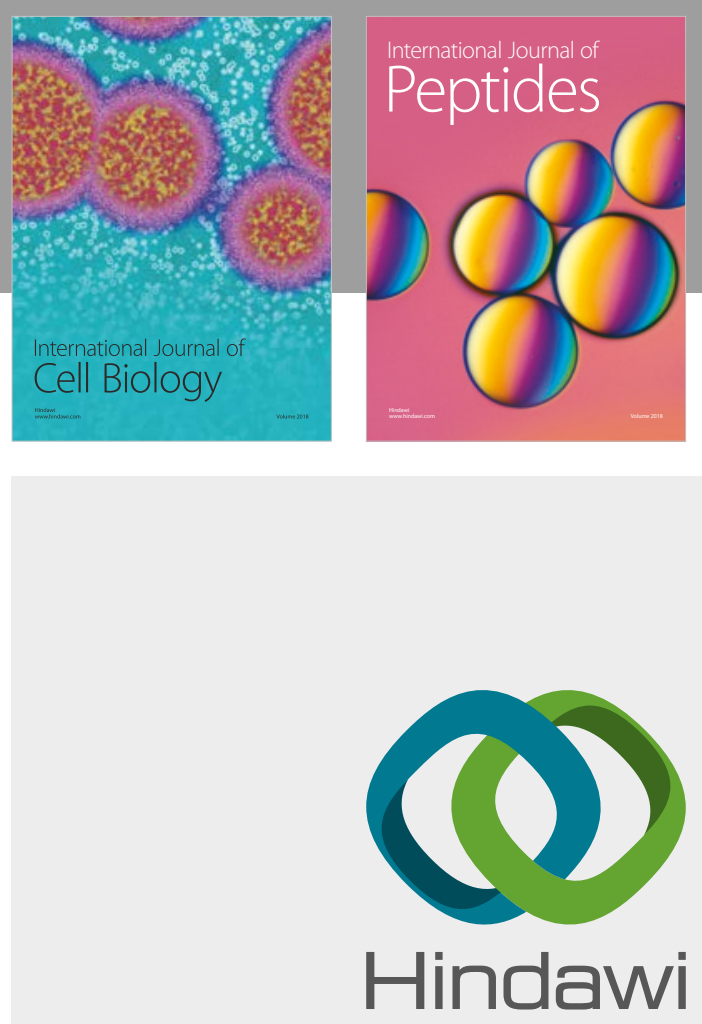

Submit your manuscripts at

www.hindawi.com
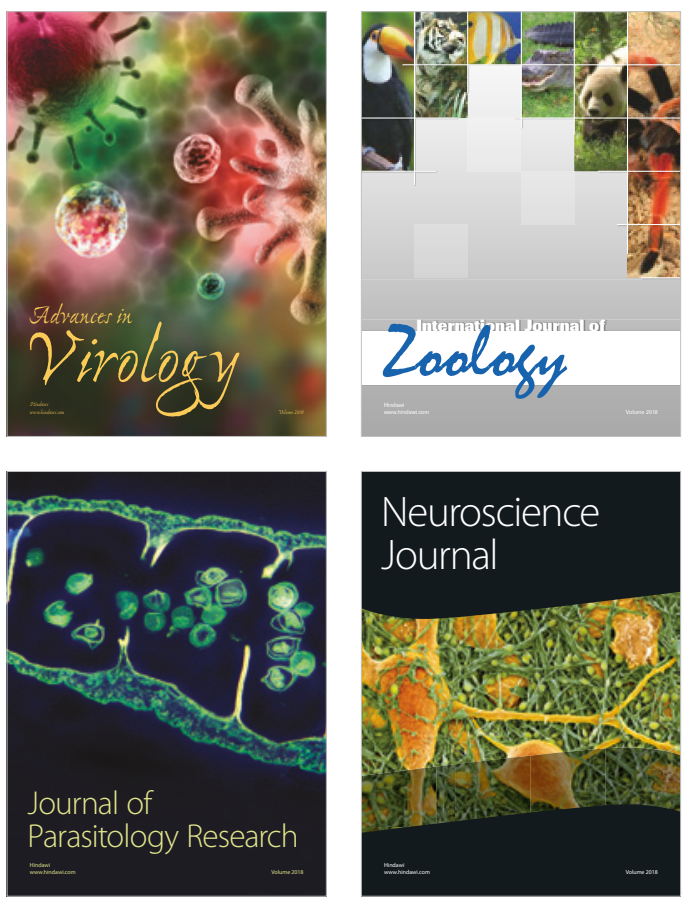
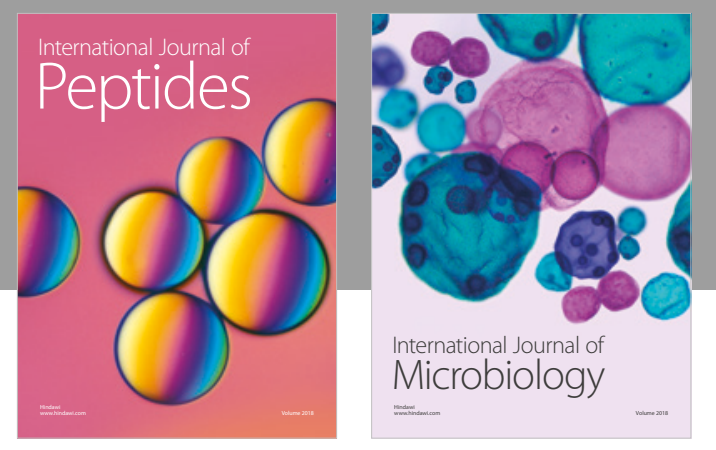

nternational Journal of Microbiology
Journal of
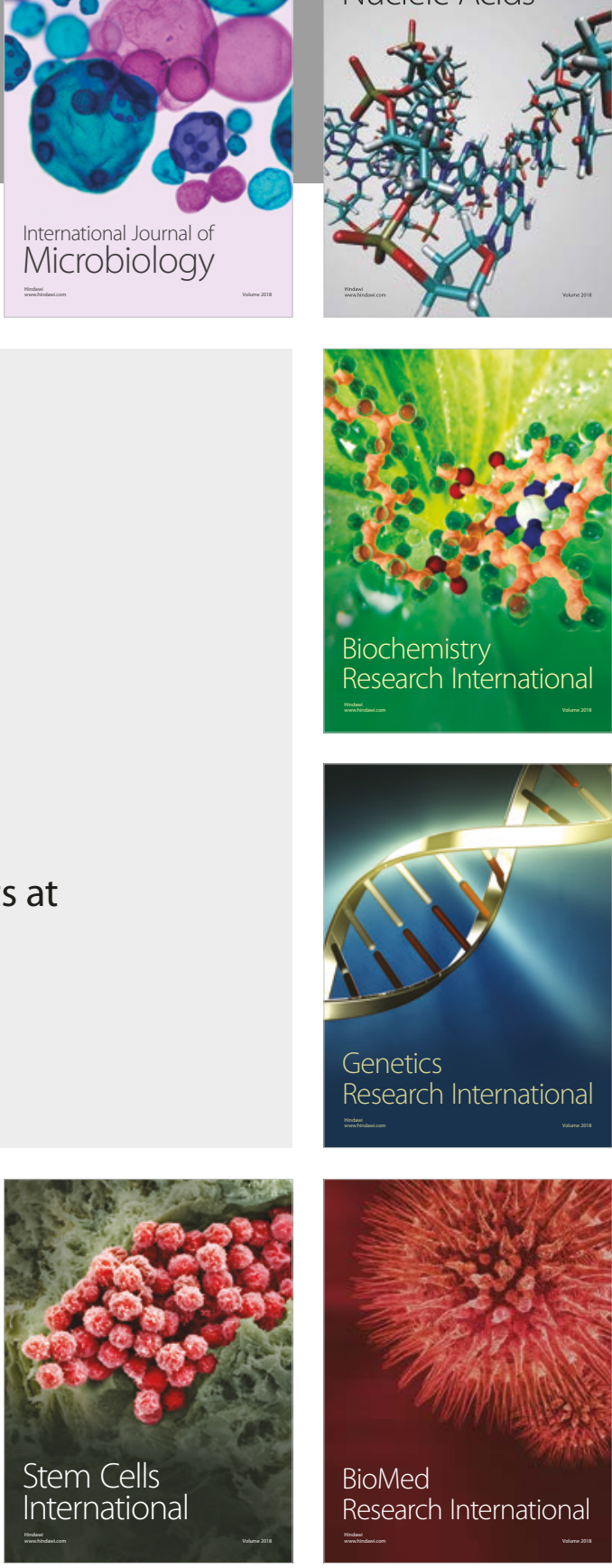
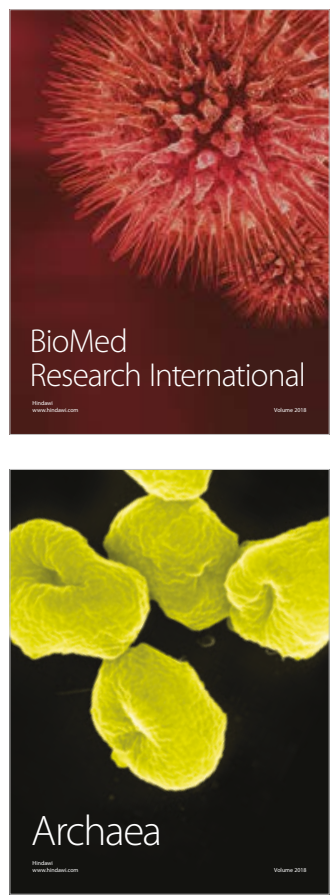